\title{
Vascular endothelial growth factor receptor-I mediates migration of human colorectal carcinoma cells by activation of Src family
} kinases

\section{DP Lesslie III', , JM Summy², NU Parikh², F Fan², JG Trevino ${ }^{1,2}$, TK Sawyer ${ }^{3}$, CA Metcalf III', WC Shakespeare ${ }^{3}$, DJ Hicklin ${ }^{4}$, LM Ellis ${ }^{1,2}$ and GE Gallick ${ }^{*, 2}$}

'Department of Surgical Oncology, The University of Texas MD Anderson Cancer Center, 15 I 5 Holcombe Boulevard, Houston, TX, USA; ${ }^{2}$ Department of Cancer Biology, I 15 Holcombe Boulevard, Houston, TX, USA; ${ }^{3}$ Ariad Pharmaceuticals, Cambridge, MA, USA; ${ }^{4}$ ImClone Systems, New York, NY, USA

Vascular endothelial growth factor (VEGF) is the predominant pro-angiogenic cytokine in human malignancy, and its expression correlates with disease recurrence and poor outcomes in patients with colorectal cancer. Recently, expression of vascular endothelial growth factor receptors (VEGFRs) has been observed on tumours of epithelial origin, including those arising in the colon, but the molecular mechanisms governing potential VEGF-driven biologic functioning in these tumours are not well characterised. In this report, we investigated the role of Src family kinases (SFKs) in VEGF-mediated signalling in human colorectal carcinoma (CRC) cell lines. Vascular endothelial growth factor specifically activated SFKs in HT29 and KMI2L4 CRC cell lines. Further, VEGF stimulation resulted in enhanced cellular migration, which was effectively blocked by pharmacologic inhibition of VEGFR-I or Src kinase. Correspondingly, migration studies using siRNA clones with reduced Src expression confirmed the requirement for Src in VEGFinduced migration in these cells. Furthermore, VEGF treatment enhanced VEGFR-I/SFK complex formation and increased tyrosine phosphorylation of focal adhesion kinase, pI30 cas and paxillin. Finally, we demonstrate that VEGF-induced migration is not due, at least in part, to VEGF acting as a mitogen. These results suggest that VEGFR-I promotes migration of tumour cells through a Srcdependent pathway linked to activation of focal adhesion components that regulate this process. British Journal of Cancer (2006) 94, 1710-1717. doi:10.1038/sj.bjc.6603143 www.bjcancer.com Published online 9 May 2006

(c) 2006 Cancer Research UK

Keywords: VEGFR-I; VEGF; Src kinase; colorectal cancer

Three distinct receptor tyrosine kinases bind vascular endothelial growth factor (VEGF): vascular endothelial growth factor receptor (VEGFR)-1 (Flt-1), VEGFR-2 (Flk-1/KDR) and VEGFR-3 (Flt-4). Vascular endothelial growth factor receptor 1 and VEGFR-2 are expressed primarily on vascular endothelial cells, while VEGFR-3 is expressed primarily on lymphatic endothelial cells and regulates lymphangiogenesis (Irrthum et al, 2000). Vascular endothelial growth factor receptor 2 is believed to be the major mediator of angiogenesis in human malignancy, as it regulates activation of downstream effector molecules such as phosphoinositide 3-kinase and AKT, and potentiates endothelial differentiation, DNA synthesis and proliferation (Waltenberger et al, 1994; Meyer and Rahimi, 2003). Vascular endothelial growth factor receptor 1 appears to function as a VEGF 'sink' during developmental vasculogenesis, but may contribute to angiogenesis in pathologic states such as ischaemia or malignancy (Hiratsuka et al, 1998, 2001; Carmeliet et al, 2001; Hayashibara et al, 2001).

*Correspondence: Dr GE Gallick, Department of Cancer Biology, Box \#173, The University of Texas MD Anderson Cancer Center, 15I5 Holcombe Blvd., Houston, TX 77030-4009, USA;

E-mail: ggallick@mdanderson.org

Received I4 October 2005; revised 6 March 2006; accepted 5 April 2006; published online 9 May 2006
In addition to their expression on endothelial cells, VEGFRs are also expressed on cells of haematopoietic origin and have recently been demonstrated on a variety of tumour types, including prostate, ovarian, melanoma, non-small-cell lung, pancreatic and colon (Decaussin et al, 1999; Ferrer et al, 1999; Masood et al, 2001). While the functions of VEGFRs on tumour cells are not completely understood, the concomitant production of VEGF and VEGFR expression by tumour cells suggests the possibility that these receptors mediate biologic functions in tumour cells. Indeed, in cancers of the breast and skin (melanoma) and in some leukaemias, VEGF/VEGFR autocrine signalling loops have been identified (Bellamy et al, 1999; Dias et al, 2000, 2001; Lacal et al, 2000 ), but the elucidation of the contribution of individual VEGF/ VEGFR family members to biologic functions mediated by individual receptors is only beginning to emerge. In a recent work, Wang et al (2004) demonstrated differential regulation of lymphoma xenografts utilising species-specific receptor antibodies to VEGFR-1 and VEGFR-2. In that study, targeting tumourassociated VEGFR-1 (human xenografted cells) increased apoptosis and diminished tumour growth, while targeting host (i.e. murine) VEGFR-2 diminished microvascular density (Wang et al, 2004). Also, inhibition of VEGFRs with a synthetic binding antagonist inhibited growth in xenograft models of colon and other tumours (Ueda et al, 2005). Individual receptor ligands may elicit different biologic responses as well. In $P l G F-I-$ mice, 
VEGF-B (another VEGFR-1 ligand) failed to rescue vascular development, suggesting that differential responses occur depending on which ligand binds the receptor in vivo (Carmeliet et al, 2001).

Signalling pathways mediated by VEGFRs in both endothelial and tumour cells are now being delineated. In endothelial cells, the Src family kinases (SFKs), Src and Yes are required for VEGFinduced vascular permeability and survival (Eliceiri et al, 1999). Likewise, VEGF-induced Src activation and signalling has been reported in Kaposi's sarcoma cells (Munshi et al, 2000). However, the possibility that VEGFRs require SFKs to mediate their biologic effects in other tumours has not been established.

When bound to receptor protein tyrosine kinases, SFKs become activated. Activation of SFKs has been implicated in progression and metastasis of a variety of solid tumours (reviewed by Summy and Gallick, 2003). Experiments in colorectal cancer have demonstrated increasing Src kinase activity with progression from adenoma to dysplasia to carcinoma and, finally, to metastatic disease (Talamonti et al, 1993), suggesting a role for Src in regulating colon tumour progression. Additionally, Src kinase activity and VEGF have both been associated with poor prognosis in patients with advanced colorectal cancer (Takahashi et al, 1997; Werther et al, 2000; Allgayer et al, 2002). Thus, the potential of VEGFRs to signal through SFKs in colorectal cancer may be of clinical significance.

The purpose of this study was to determine whether SFKs must be activated in order for VEGFRs to mediate biologic effects. We tested the effects of VEGFR signalling through SFKs on cellular migration and proliferation in human colorectal cancer cells. We found that migration, but not proliferation, was significantly increased, suggesting the potential role of VEGFR-1 expression in tumour progression in these cells.

\section{MATERIALS AND METHODS}

\section{Cell culture}

HT29 cells derived from a human colon adenocarcinoma were maintained as a subconfluent monolayer in Dulbecco's modified Eagle's medium (DMEM/F12) with Earle's salts and $2 \mathrm{mM}$ glutamine (Life Technologies, Inc., Grand Island, NY, USA) supplemented with $10 \%$ foetal bovine serum (Hyclone Laboratories, Logan, UT, USA) without antibiotics and incubated in $5 \%$ $\mathrm{CO}_{2} / 95 \%$ air at $37^{\circ} \mathrm{C}$. Highly metastatic KM12L4 human colorectal carcinoma (CRC) cells were kindly provided by IJ Fidler, $\mathrm{PhD}$, DVM (The University of Texas MD Anderson Cancer Center, Houston, TX, USA). Cells were cultured and maintained in minimal essential medium (MEM) supplemented with $10 \%$ foetal bovine serum (Hyclone Laboratories), $2 \mathrm{U} \mathrm{ml}^{-1}$ of a penicillinstreptomycin mixture (Flow Laboratories, Rockville, MD, USA), vitamins (Life Technologies, Inc., Grand Island, NY, USA), $1 \mathrm{~mm}$ sodium pyruvate, $2 \mathrm{~mm}$ L-glutamine and nonessential amino acids, and incubated in $5 \% \mathrm{CO}_{2} / 95 \%$ air at $37^{\circ} \mathrm{C}$.

\section{Creation of siRNA expression plasmids silencing Src gene expression}

SiRNA expression plasmids were created using the Ambion pSilencer 1.0-U6 (Austin, TX, USA) according to the manufacturer's directions. c-Src specific target sequences were designed using the Ambion siRNA web design tool. The two target sequences utilised were $(52-71 \mathrm{bp}) 5^{\prime}$-AACAAGAG CAAGCC CAAGGAT- $3^{\prime}$ and $(226-244 \mathrm{bp})$ 5'-AAGCTGTTCGGAGGCTT CAAC- $3^{\prime}$. Oligonucleotides corresponding to these sequences with flanking Apal $\left(5^{\prime}\right)$ and EcoR1 $\left(3^{\prime}\right)$ ends were purchased from Invitrogen/Life Technology (Carlsbad, CA, USA) and ligated into the expression plasmid at compatible sites. Constructs were confirmed by DNA sequencing. HT29 cells were then transfected with $500 \mathrm{ng}$ of each siRNA plasmid and $100 \mathrm{ng}$ of pcDNA G418 resistance promoter-less plasmid for selection of transfectants. Cells were then grown in selective media containing G418 as described previously (Ahmad et al, 2001). Negative controls were transfected with empty vector target sequences and pcDNA plasmids at identical concentrations. Total c-Src expression levels in siRNA clones were determined by Western blot analysis.

\section{Inhibitors/recombinant growth factors}

The novel, selective, potent Src kinase inhibitor, AP23464 (O'Hare et al, 2004; Brunton et al, 2005; Corbin et al, 2005; Summy et al, 2005), or the commercially available Src kinase inhibitor, 4-amino5-(4-chlorophenyl)-7-( $t$-butyl)pyrazolo(3,4-d)pyrimidine (PP2) (Calbiochem, San Diego, CA, USA) suspended in 1\% dimethyl sulphoxide (DMSO) at desired concentrations and the VEGFR-1 monoclonal blocking antibody IMC-18F1 were used in this study. The recombinant human growth factors VEGF-A and VEGF-B (R\&D Systems, Minneapolis, MN, USA) were used at 10 and $50 \mathrm{ng} \mathrm{ml}^{-1}$, respectively, unless noted otherwise.

\section{Cell lysis}

Cells in log growth phase at $50 \%$ confluency were serum starved overnight and exposed to the VEGFR-1 blocking antibody IMC$18 \mathrm{~F} 1\left(20 \mu \mathrm{g} \mathrm{ml}^{-1}\right)$, or AP23464 $(1 \mu \mathrm{M})$ was added to culture media for $1 \mathrm{~h}$ at $37^{\circ} \mathrm{C}$. Recombinant VEGF-A or -B or PBS control was then added at the desired concentration, and, at the desired time, cells were rinsed twice with ice-cold PBS and then lysed with RIPAB lysis buffer (20 mM sodium phosphate, $150 \mathrm{~mm} \mathrm{NaCl}, 5 \mathrm{~mm}$ EDTA, $1 \%$ Triton X-100, $0.5 \%$ sodium deoxycholate) supplemented with one tablet complete mini-EDTA protease inhibitor cocktail (Roche Diagnostic, Manheim, Germany) and $1 \mathrm{~mm}$ sodium orthovanadate $(\mathrm{pH} 7.4)$. Cells were harvested with the aid of a rubber policeman, clarified by centrifugation at $13000 \mathrm{~g}$ for $15 \mathrm{~min}$ at $4{ }^{\circ} \mathrm{C}$, and prepared for Western blot analysis or immunoprecipitation, as described previously (Windham et al, 2002).

\section{Immunodepletion assay}

Cleared cell lysates ( $250 \mu$ g protein) were incubated overnight at $4^{\circ} \mathrm{C}$ with $10 \mu \mathrm{l}$ anti-VEGFR-1 antibody (Oncogene Research Products, Cambridge, MA, USA) or $10 \mu \mathrm{l}$ antimouse IgG (Organon Teknika, Durham, NC, USA). Immune complexes were formed by the addition of $50 \mu \mathrm{l}$ protein A:G agarose beads for $2 \mathrm{~h}$ at $4{ }^{\circ} \mathrm{C}$. The remaining soluble lysates were centrifuged at $13000 \mathrm{~g}$ for $2 \mathrm{~min}$ and the supernatants were collected for immunoblotting.

\section{Immunoprecipitation and immune complex kinase assay}

Cleared cell lysates (500 $\mu$ g protein) were incubated overnight at $4{ }^{\circ} \mathrm{C}$ with $10 \mu \mathrm{l}$ of $\mathrm{Src}$ monoclonal antibody 327 (Oncogene Research Products, Cambridge, MA, USA), $10 \mu \mathrm{l}$ Yes antibody 1B7 (WAKO Biologicals, Richmond, VA, USA) or $6 \mu \mathrm{l}$ focal adhesion kinase (FAK) antibody (clone 2A7, Upstate Biotechnology, Lake Placid, NY, USA). Immune complex kinase assays were performed as described previously (Windham et al, 2002). Briefly, immune complexes were formed by the addition of $10 \mu \mathrm{l}$ of rabbit antimouse IgG (Organon Teknika, Durham, NC, USA) for $2 \mathrm{~h}$, followed by $50 \mu \mathrm{l}$ of $10 \%\left(\mathrm{vv}^{-1}\right)$ formalin-fixed Pansorbin (Staphylococcus aureus, Cowan strain; Calbiochem, La Jolla, CA, USA) for $60 \mathrm{~min}$. Pellets were then washed three times in a buffer consisting of $0.1 \%$ Triton $\mathrm{X}-100,150 \mathrm{~mm} \mathrm{NaCl}$ and $10 \mathrm{~mm}$ sodium phosphate. Reactions were initiated at $22^{\circ} \mathrm{C}$ by the addition of $10 \mu \mathrm{Ci}$ of $\left[\gamma^{32} \mathrm{P}\right] \mathrm{ATP}, 10 \mathrm{mM} \mathrm{Mg}^{2+}$ and $100 \mu \mathrm{M}$ sodium orthovanadate in $20 \mathrm{~mm}$ HEPES buffer to each sample. To analyse phosphorylation of an exogenous substrate, $10 \mu \mathrm{g}$ of rabbit muscle enolase (Sigma-Aldrich, St Louis, MO, USA) was added to the 
reaction buffer. After $10 \mathrm{~min}$, reactions were terminated by the addition of SDS sample buffer. Proteins were separated by SDS PAGE on $8 \%$ polyacrylamide gels, and radioactive proteins were detected by autoradiography.

\section{Immunoblotting}

Proteins $(50 \mu \mathrm{g})$ from clarified cell lysates were separated via $8 \%$ SDS-PAGE and electroblotted onto polyvinylidene difluoride membranes (Amersham Corp., Chicago, IL, USA). The membranes were blocked with Tris-buffered saline/Tween $(0.15)+5 \%$ dried milk for $30 \mathrm{~min}$ at room temperature and probed with the desired primary antibody diluted $1: 1000$ in blocking buffer overnight at $4{ }^{\circ} \mathrm{C}$. Membranes were probed with antibodies to Src mAb\#327 (Oncogene Research Products), Yes Ab 1B7 (WAKO Biologicals), phospho $\mathrm{FAK}^{\mathrm{Y} 397}$ (Biosource International, Camarillo, CA, USA), phospho $\mathrm{FAK}^{\mathrm{Y} 861}$ (Biosource International), FAK (BD Transduction, San Jose, CA, USA), Akt (5G3, Cell Signaling Technology, Beverly, MA, USA), phospho-Akt ${ }^{\mathrm{S} 473}$ (Cell Signaling Technology), p42/44 Erk MAPK (Cell Signaling Technology), phospho-p42/44 Erk $^{\mathrm{T} 202 / \mathrm{Y} 204}$ (Cell Signaling Technology), VEGFR-1 (Oncogene Research Products), paxillin (Cell Signaling Technology), phospho-paxillin ${ }^{\mathrm{Y} 118}$ (Cell Signaling Technology), p130 cas (BD Transduction), phospho-p130 cas/Y165 (Cell Signaling Technology), phosphotyrosine (4G10, Upstate, Lake Placid, New York, NY, USA) and vinculin (Sigma-Aldrich). Primary antibody incubation was followed by incubation with a horseradish peroxidaseconjugated secondary antibody (Bio-Rad goat anti-mouse, sheep anti-rabbit or rabbit anti-goat; Bio-Rad laboratories, Hercules, CA, USA) diluted 1:3000 in blocking buffer for $1 \mathrm{~h}$ at room temperature. Proteins were visualised with electrochemiluminescence detection reagents (Perkin-Elmer, Boston, MA, USA) and detected with autoradiography.

\section{Proliferation assay}

3-(4,5-Dimethylthiazol-2-yl)-2,5-diphenyltetrazolium bromide (M2128) (Sigma Chemical Corp., St Louis, MO, USA) was prepared by dissolving $5 \mathrm{mg}$ M2128 in $1 \mathrm{ml}$ PBS. The solution was protected from light and stored at $4{ }^{\circ} \mathrm{C}$. To determine proliferation, HT29 cells $\left(1.5 \times 10^{3}\right.$ cells $)$ were seeded into 96 -well plates in quintuplicate and allowed to adhere overnight in 10\% complete DMEM/F12. The medium was then removed and replaced with $0.2 \mathrm{ml}$ of media containing VEGF-A supplemented with solvent control, IMC-18F1 or AP23464 and allowed to incubate at $37^{\circ} \mathrm{C}$. At the desired time point, $50 \mu \mathrm{l}$ of prepared MTT solution was added to each well and incubated at $37^{\circ} \mathrm{C}$ for $2 \mathrm{~h}$. The media was removed carefully and the cells were solubilised in $0.2 \mathrm{ml}$ DMSO. Plates were read using spectrophotometric analysis at a wavelength of $570 \mathrm{~nm}$ using the TECAN Genios plate reader and Magellan version 4.0 software. Results are representative of three independent experiments.

\section{Migration assay}

The modified Boyden chamber migration assay was used as described previously (Minard et al, 2005). Cells $\left(2.5 \times 10^{5}\right.$ cells) were suspended in the upper well of the migration chamber (control inserts, $8 \mu \mathrm{m}$ pore size; Becton-Dickinson, Bedford, MA, USA) in $0.5 \mathrm{ml}$ of serum-free media. The lower chamber was filled with $0.75 \mathrm{ml}$ of media with VEGF-A $\left(10 \mathrm{ng} \mathrm{ml}^{-1}\right)$ supplemented with DMSO control, IMC-18F1 $\left(20 \mu \mathrm{g} \mathrm{ml}^{-1}\right)$ or AP23464 $(1 \mu \mathrm{M})$. After $72 \mathrm{~h}$ of incubation, the nonmigratory colon carcinoma cells on the upper filter surface were removed with a cotton swab, and cells that had migrated to the lower filter were fixed and stained with HEMA 3 (Biochemical Sciences, Swedesboro, NJ, USA) according to the manufacturer's instructions. The migratory cells were counted under a microscope at $\times 100$ magnification. Cell images were obtained using a Sony PXC-990 3CCD colour video camera (Sony of America, New York, NY, USA). Cells were counted in five random fields per insert in triplicate.

\section{Statistical analyses}

Statistical differences among groups were examined using the two-tailed Student's $t$-test. $P<0.05$ was considered statistically significant.

\section{RESULTS}

\section{VEGF induces SFK activation in human CRC cells}

A variety of growth factors are known to induce SFK activation in endothelial cells. We examined HT29 and KM12L4 human CRC cells to determine whether Src and Yes, the SFK members principally expressed in these cells (Cartwright et al, 1989; Park et al, 1993), are activated by VEGF-A. As measured by immune complex kinase assay, treatment of HT29 cells with VEGF-A $\left(10 \mathrm{ng} \mathrm{ml}^{-1}\right)$ increased both Src and Yes kinase activity in a timedependent manner (Figure 1A). Maximal activation ( $\sim 2.5$-fold increase) was observed within $15 \mathrm{~min}$, which is consistent with $\mathrm{Src}$ activation by a number of ligands. Src expression did not change during the time period analysed, consistent with our postulate that VEGF-A increases specific activity of these SFKs. As shown in Figure 1B, VEGF-A also activates SFKs in a dose-dependent

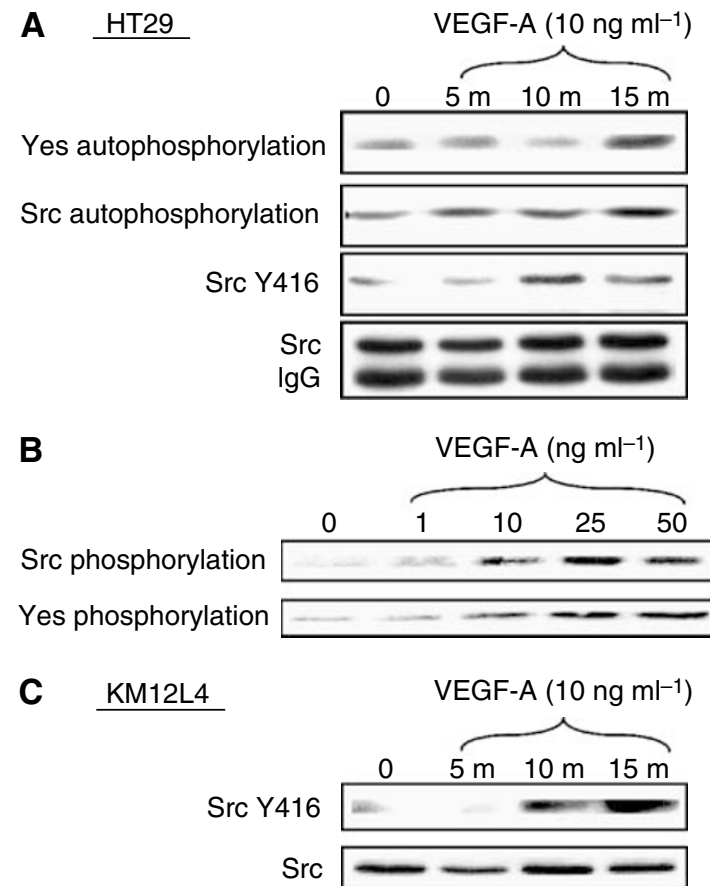

Figure I Effect of VEGF on SFK activity in human CRC cell lines. (A) Serum-starved HT29 cells at 50\% confluency were untreated (0) or stimulated with VEGF-A for 5,10 and $15 \mathrm{~min}$. Cell lysates were immunoprecipitated with anti-Src or anti-Yes antibodies and subjected to immune complex kinase assays (top two panels) or Western blotting with the phospho-specific anti-Src Y4I6 antibody. Western blotting (following immunoprecipitation) with anti-Src antibody demonstrates equivalent total Src expression (bottom panel). (B) Serum-starved HT29 cells at 50\% confluency were untreated $(0)$ or stimulated with indicated concentrations of VEGF-A for 15 min. Cell lysates were immunoprecipitated with anti-Src or anti-Yes antibodies and subjected to immune complex kinase assay. (C) KMI2L4 cell lysates were prepared and immunoblotted with SrcY4I6 antibodies and stripped and reprobed with total Src antibodies as described above. 
manner in HT29 cells, with maximal kinase activation observed at $25 \mathrm{ng} \mathrm{ml}^{-1}$. Likewise, treatment of KM12L4 human CRC cells with VEGF-A $\left(10 \mathrm{ng} \mathrm{ml}^{-1}\right)$ induced a similar increase in SFK activation (Figure 1C) as that observed in HT29 cells.

\section{VEGF-induced SFK activation occurs through VEGFR-1 in HT29 cells}

As reported previously, HT29 cells express VEGFR-1 but not VEGFR-2 or VEGFR-3 (Fan et al, 2005). To demonstrate VEGFR-1 activation and specificity of the monoclonal VEGFR-1 blocking antibody, IMC-18F1, tyrosine phosphorylation of VEGFR-1 was determined by Western blotting. As presented in Figure 2A, VEGFA treatment resulted in marked increase in tyrosine phosphorylation of a $180 \mathrm{kDa}$ cellular protein, which was effectively blocked by pretreatment with IMC-18F1, confirming the ability of IMC-18F1 to inhibit VEGFR-1 activation without altering VEGFR-1 expression levels. Next, to determine whether activation of SFKs was mediated by VEGFR-1, SFK activity with VEGF-A (ligand for both VEGFR-1 and -2) and the VEGFR-1 specific ligand VEGF-B was examined in the presence or absence of IMC-18F1. As shown in Figure 2B and C, VEGF-A and -B induced similar SFK activation at the doses indicated; however, pre-incubation of HT29 cells with IMC-18F1 $\left(20 \mu \mathrm{g} \mathrm{ml}^{-1}\right)$ abrogated Src and Yes activation by both VEGF-A and -B, demonstrating that functional VEGFR-1 is required for VEGF-mediated SFK activation.

Increased activity of SFKs usually results from direct association with the cognate receptor. To determine whether VEGF induces SFK/VEGFR-1 complexes, co-immunoprecipitation experiments were performed with VEGF stimulation in the presence or absence of VEGFR-1 blocking antibody. As demonstrated in Figure 2D, VEGF greatly enhanced SFK/VEGFR-1 complex formation, and this association was effectively blocked by pretreatment with IMC18F1. Immune complexes were not detectable when using an irrelevant IgG antibody (data not shown). Taken together, these results suggest that increased SFK activity may result from direct interaction with VEGFR-1, though other mechanisms might account for increased Src activity as well.

\section{VEGF induces migration of human CRC cells}

Src family members have been implicated in numerous biologic activities, including proliferation and migration (reviewed by Brown and Cooper, 1996; Thomas and Brugge, 1997). To identify the potential biologic effects mediated by VEGFR-1 expression, we first assessed cellular migration in response to VEGF-A, utilising a modified Boyden chamber as described in Materials and Methods (Figure 3). As demonstrated in Figures $3 \mathrm{~B}$ and D, VEGF-A treatment of HT29 and KM12L4 human CRC cells resulted in a five- and three-fold increases in cellular migration, respectively,

Figure 2 Requirement for VEGFR-I for Src activation by VEGF-A and VEGF-B. (A) Lysates from VEGF-treated cells in the presence or absence of the VEGFR-I blocking antibody, IMC-I8FI, following immunodepletion with anti-VEGFR-I antibody (first lane) or nonspecific lgG (second and third lanes) were prepared, and the resultant supernatants were subjected to Western blotting with anti-phosphotyrosine antibody or anti-VEGFR-I antibody. (B, C) Serum-starved HT29 cells at 50\% confluency were pretreated with IMC-I8FI or PBS control for I h and were untreated (0) or stimulated with VEGF-A or VEGF-B for 10, 15 and 30 min. Cell lysates were immunoprecipitated with anti-Src or anti-Yes antibodies and subjected to immune complex kinase assay or subjected to Western blotting with anti-Src, anti-Yes or anti-VEGFR-I antibodies to demonstrate the lack of effect on expression of these proteins. (D) Lysates from VEGFA-treated cells in the presence or absence or $|\mathrm{MC}-| 8 \mathrm{FI}$ were immunoprecipitated with anti-VEGFR-I antibody. The resultant immunoprecipitates were run on SDS-PAGE and subjected to Western blotting with antibodies to Src, Yes or VEGFR-I. over nontreated control cells $(P<0.001)$. Pharmacologic blockade of VEGFR-1 with IMC-18F1 or Src kinase inhibition with AP23464 or PP2 completely inhibited VEGF-induced migration in both cell lines $(P<0.001)$, again demonstrating the requirement of SFK activation through VEGFR-1 in this process.

\section{Effects of Src-targeted siRNA on VEGF-induced migration of CRC}

To independently confirm the requirement for Src in mediating VEGF-A-induced migration, the ability of this ligand to affect

A



B
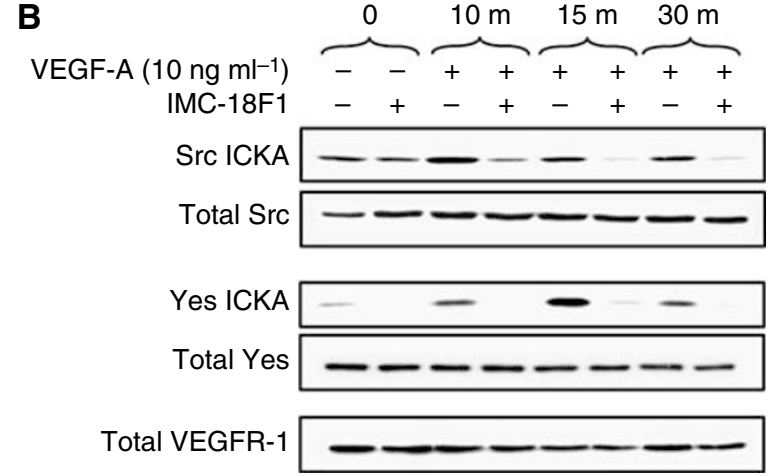

C

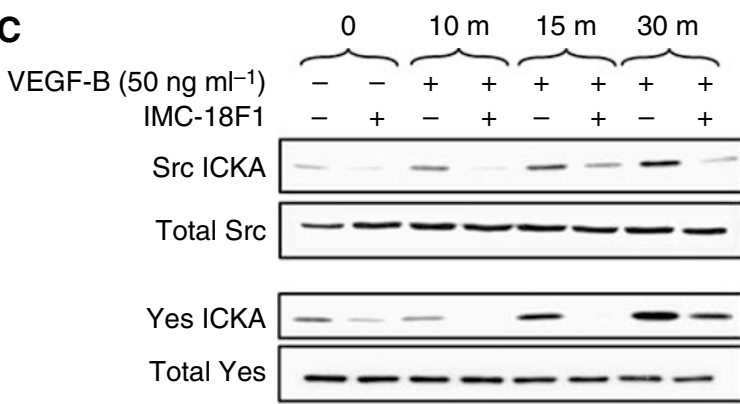

Total VEGFR-1 _ _

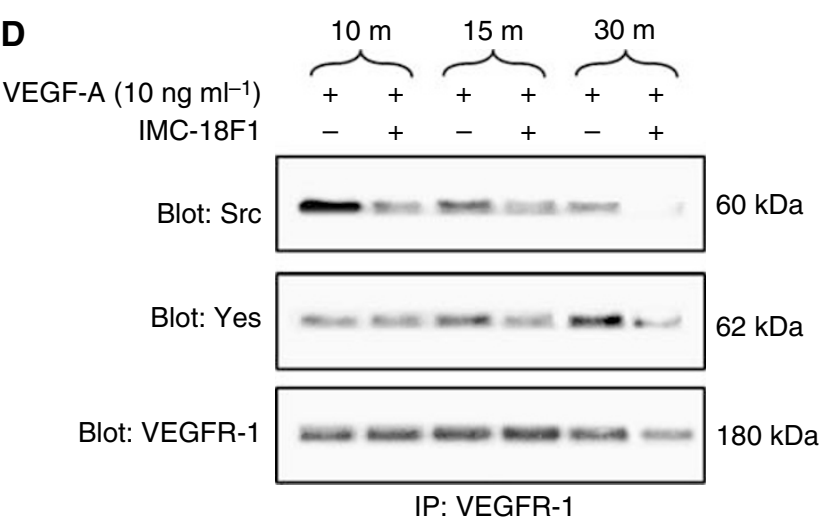

IP: VEGFR-1 
A


HT29
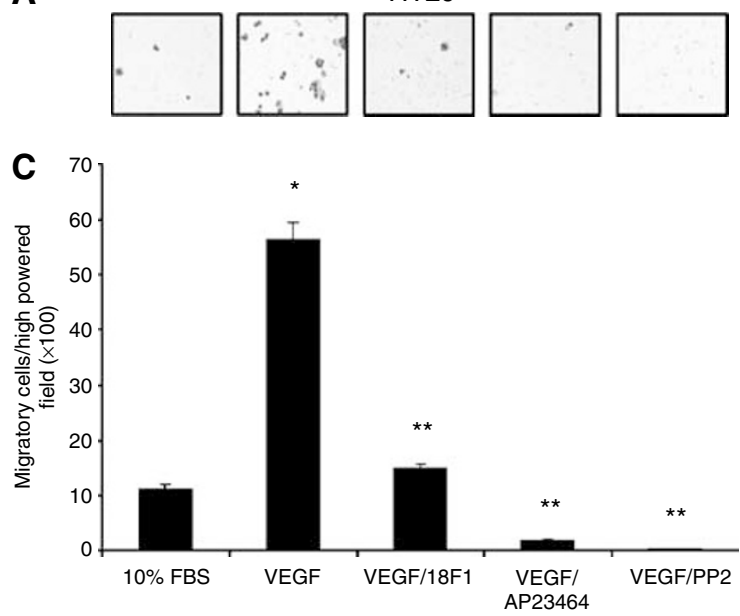

B
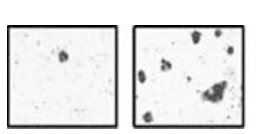

KM12L4
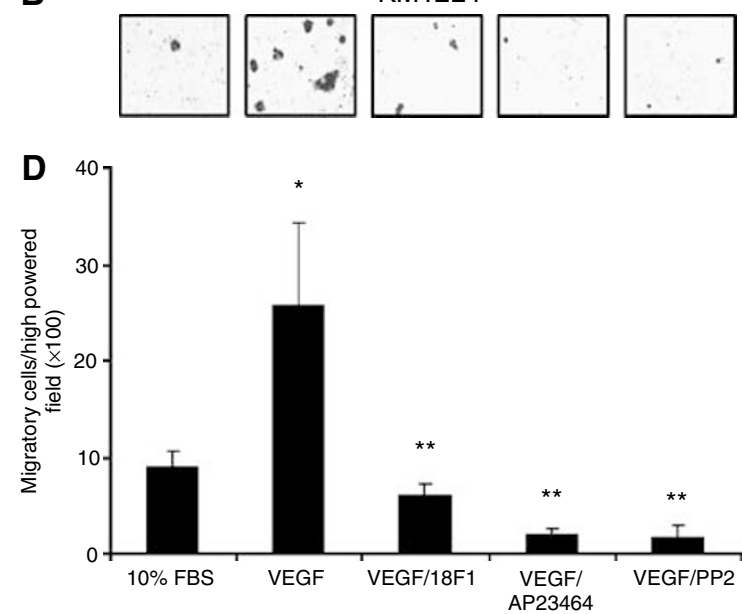

Figure 3 Effects of VEGF-mediated SFK activation on CRC migration. HT29 and KMI LL4 CRC cells were pretreated with IMC- I8FI $\left(20 \mu \mathrm{g} \mathrm{ml} \mathrm{I}^{-1}\right)$, the novel, potent Src kinase inhibitor, AP23464 (I $\mu \mathrm{M})$, a commercially available Src inhibitor, PP2 (I0 $\mu \mathrm{M})$ or PBS control for I h and allowed to migrate in a modified Boyden chamber containing VEGF-A $\left(10 \mathrm{ng} \mathrm{ml}^{-1}\right)$ or I $0 \%$ FBS for $72 \mathrm{~h}$. (A, B) Representative photos of migrated cells $(\times 100 \mathrm{magnification})$. (C, D) Quantitation of migrated cells. $* P<0.00$ I vs control cells. $* * P<0.00$ I vs cells treated with VEGF alone. Bars represent s.e.m.

migration in HT29 clones reduced in Src by stable expression of an antisense expression vector was determined. As shown in Figure 4A, two independent clones (siRNA cl.18 and 23) were reduced by more than $80 \%$ in Src expression. These cells were considerably reduced in their migratory abilities (Figure 4B), consistent with Src being important in cellular migration, and addition of VEGF-A did not increase migratory capability of these cells (Figure 4C), providing further evidence that VEGF mediates migration through Src activation. Basal proliferation of these cells as determined by MTT assay did not differ significantly from nontransfected parental cells (data not shown).

\section{VEGF activates FAK, p130 ${ }^{\text {cas }}$ and paxillin in HT29 cells}

In epithelial and fibroblast cells, migration is regulated, in part, by activation of FAK. Recent studies in endothelial cells have implicated FAK as required for VEGFR-1-induced tubulogenesis (Maru et al, 2001). Src/FAK activation then leads to phosphorylation of both paxillin and $130^{\text {cas }}$. To determine if FAK were activated upon treatment of HT29 cells with VEGF, both FAK immune complex kinase assays and Western blot analysis for specific FAK phosphorylation sites were performed as described in Materials and Methods. As presented in Figure 5A, VEGF treatment of HT29 cells increased both autophosphorylation of FAK and phosphorylation of the exogenous substrate enolase twofold at $30 \mathrm{~min}$. As enolase phosphorylation may also result from Src being immunoprecipitated in the immune complexes, we directly examined phosphorylation of Y861 and Y397 in response to VEGF stimulation of HT29 cells. Phosphorylation of Y861, and to a lesser extent Y397, was increased, and these increases were blocked by prior addition of IMC-18F1. These findings are consistent with previous experimental work in VEGFR-1 overexpressing fibroblasts (Maru et al, 2001) and suggest crosstalk between VEGFR-1 and FAK in HT29 cells. As shown in Figure 5B and C, VEGF treatment of HT29 cells also increased tyrosine phosphorylation of both paxillin and p130 ${ }^{\text {cas }}$. Maximal phosphorylation occurred within 15-30 min, consistent with the kinetics of Src and Yes activation. Pretreatment of HT29 cells with IMC-18F1 effectively blocked FAK, paxillin and $\mathrm{p} 130^{\text {cas }}$ phosphorylation, confirming the requirement of VEGFR-1 for VEGF-induced activation of these substrates. Together, these results suggest that a VEGFR-1/SFK complex interacts with components of focal adhesions, thus mediating cellular migration in HT29 cells.
A
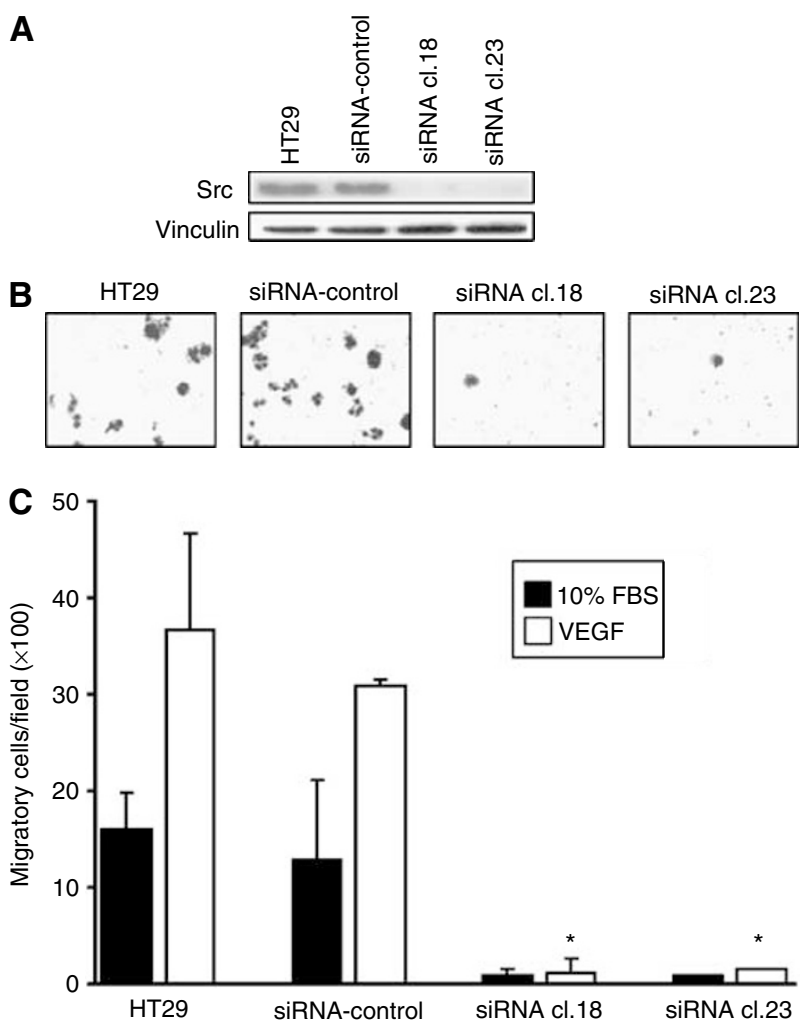

Figure 4 Effects of Src-targeted siRNA on VEGF-induced CRC migration. (A) HT29 parental cells and stable G4I8-resistant clones expressing either empty vector (siRNA control) or Src-targeted siRNA were subjected to Western blot analysis with antibodies to total Src. Membranes were stripped and reprobed with anti-vinculin antibody as a loading control. Parental HT29, siRNA control, siRNA cl. 18 and siRNA cl. 23 cells were placed in a modified Boyden chamber containing VEGF-A $\left(10 \mathrm{ng} \mathrm{ml}^{-1}\right)$ or $10 \% \mathrm{FBS}$ for $72 \mathrm{~h}$. (B) Representative photos of VEGF-Atreated cells ( $\times 100$ magnification). (C) Quantitation of migrated cells. *P $<0.001$ vs VEGF-treated siRNA control.

\section{VEGF does not induce proliferation in HT29 cells}

Finally, to determine if VEGF-induced migration could be accounted for, at least in part, by VEGF acting as a mitogen, we 


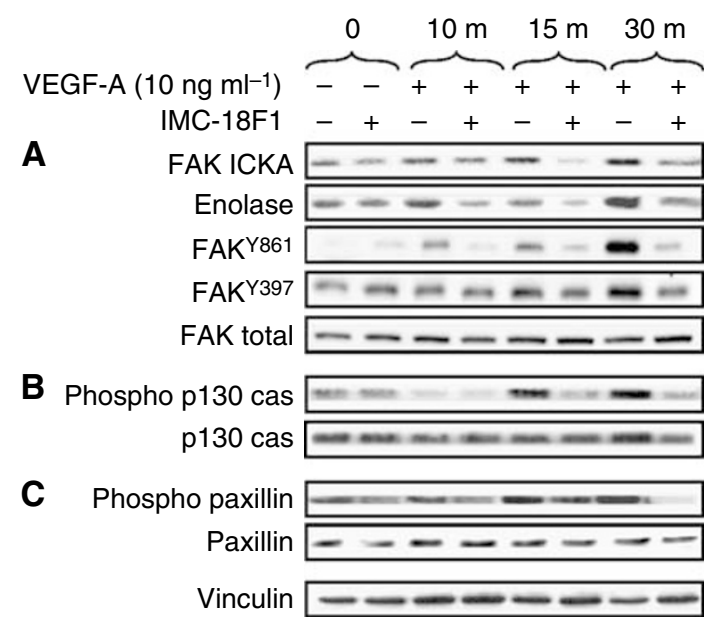

Figure 5 Effects of VEGF on phosphorylation of FAK, p/30 cas and paxillin in CRC. Serum-starved HT29 cells at 50\% confluency were pretreated with the VEGFR-I blocking antibody (IMC-I 8FI) or PBS control for I h and were untreated (0) or stimulated with VEGF-A for I0, I5 and $30 \mathrm{~min}$. Cell lysates were immunoprecipitated with anti-FAK antibody and subjected to immune complex kinase assay with enolase as an exogenous substrate or subjected to Western blotting with anti-phospho-FAK Y86I, anti-phospho-FAK Y397 or anti-FAK antibodies as indicated $(\mathbf{A})$, run on SDS-PAGE and subjected to Western blotting with anti-phospho-p I $30^{\text {cas }}$ or anti-p I $30^{\text {cas }}$ antibodies (B) or subjected to Western blotting with antiphospho-paxillin or anti-paxillin antibodies $(\mathbf{C})$. Western blot for vinculin is included to demonstrate equivalent protein loading.

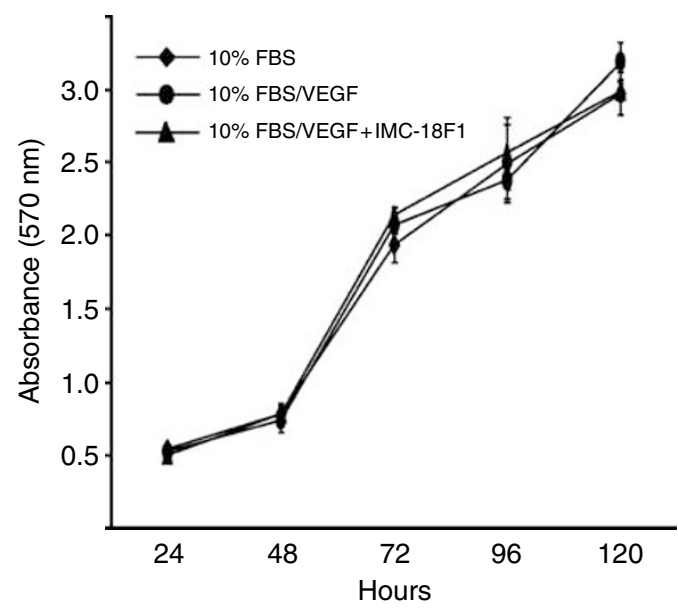

Figure 6 Effects of VEGF on CRC proliferation. HT29 cells $\left(2 \times 10^{3}\right)$ in 96-well plates in serum-free media were untreated or treated with VEGF-A $\left(10 \mathrm{ng} \mathrm{ml}^{-1}\right)$ in the presence of AP23464 (I $\left.\mu \mathrm{M}\right)$ or IMC-I $8 \mathrm{FI}\left(20 \mu \mathrm{g} \mathrm{m}^{-1}\right)$ and proliferation was determined by MTT assay as described in Materials and Methods. Bars represent standard error of the mean. Results are representative of three independent experiments.

examined the effect of VEGF-A stimulation on proliferation of HT29 cells. As shown in Figure 6, exogenous VEGF-A had no effect on HT29 cell proliferation, as determined by MTT assay. Likewise, pretreatment of HT29 cells with IMC-18F1 did not decrease proliferation. Consistent with these findings, VEGF-A treatment of HT29 cells induced minimal to no activation of Erk 1/2 or Akt, as assessed by Western blotting for phosphorylated (active) forms of these signalling enzymes (data not shown).

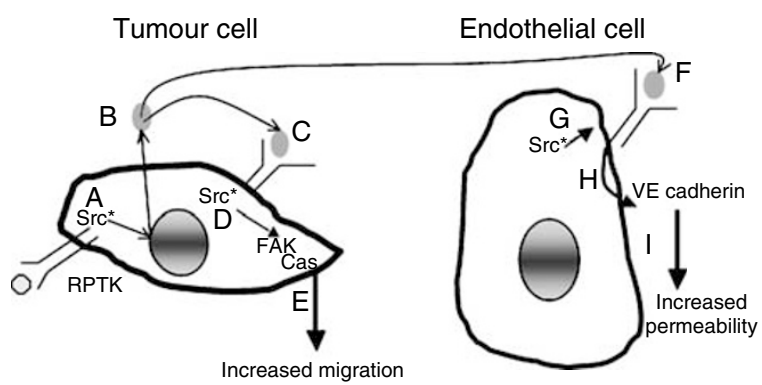

Figure 7 Model by which Src and VEGF contribute to tumour progression and metastasis through activities in both tumour and tumour-associated endothelial cells. In tumour cells (left) Src activation is frequent, resulting from overexpression of growth factor receptors, FAK and deregulated transcription (A). Src activation increases VEGF expression from tumour cells (B), leading to binding of VEGFR-I (C), association with and further activation of Src (D), and the subsequent autocrine loop contributes to tumour cell migration through FAK activation (E). Vascular endothelial growth factor produced by tumour cells also binds VEGF receptors on endothelial cells $(\mathbf{F})$, leading to association and activation of Src in these cells $(\mathbf{G})$ and leading to increased permeability through VE cadherin phosphorylation affecting tumour cell extravasation $(\mathbf{H})$, a process critical for permeability and tumour cell extravasation (I). Thus, inhibitors of VEGF, VEGFR-I and Src may have therapeutic efficacy due to their effects in both normal and tumour cells.

\section{DISCUSSION}

Our findings of VEGF-induced SFK activation and enhanced cellular migration in human CRC cells demonstrate that functional VEGFR-1 mediates intracellular signalling and biologic behaviour in these cells. Src family kinase activation in response to VEGF has been observed in cells of endothelial origin expressing VEGFRs, and SFK members have been shown to associate with VEGFRs upon activation (Chou et al, 2002). In contrast to work in endothelial cells where Src preferentially associates with VEGFR-2 and Yes and Fyn with VEGFR-1, we observed Src and Yes kinase complex formation with VEGFR-1 upon VEGF stimulation, suggesting that at least in these tumour cells, association of SFKs with VEGFR-1 may be more promiscuous than in normal endothelial cells.

The ability of VEGF to mediate particular biologic functions appears to be cell type specific, as does expression of VEGF receptor subtypes. Many cell types exhibiting increased proliferation in response to VEGF express both VEGFR-1 and -2, or are of nonepithelial origin. The significance of aberrant expression of VEGFR-1 alone on tumours of epithelial origin remains unclear, but a recently published work found a similar lack of proliferation in VEGF-stimulated colon cancer cells expressing VEGFR-1 (Fan et al, 2005).

Interestingly, we observed a robust increase in cellular migration and tyrosine phosphorylation of FAK, paxillin and $\mathrm{p} 130^{\mathrm{cas}}$ in CRC cells with VEGF stimulation, which appears to require VEGFR-1. This is consistent with prior reports suggesting that VEGFR-1 regulates cellular migration, while VEGFR-2 mediates activation of the MAPK pathway and cellular proliferation (Barleon et al, 1996). Further, our finding of VEGF-induced FAK phosphorylation, resulting in its increased activation, is consistent with previous studies on VEGFR-1-overexpressing fibroblasts (Maru et al, 2001). This result suggests an interaction between VEGFR-1 and FAK in HT29 cells. Whether this interaction is direct or indirect remains to be determined.

Vascular endothelial growth factor is a pleuripotent cytokine that induces angiogenesis, proliferation, migration, differentiation and vascular permeability in endothelial cells (Leung et al, 1989; Millauer et al, 1993; Neufeld et al, 1999). It is secreted by most, if not all solid tumours, including those arising in colon, where it is 
the principal mediator of tumour angiogenesis and its expression correlates with both disease recurrence and poor prognosis (Takahashi et al, 1997; Werther et al, 2000). As anti-VEGF therapy has demonstrated efficacy in patients with advanced CRC (Hurwitz et al, 2004), further study of VEGF/VEGFR interactions in endothelial and, perhaps, tumour cells is warranted (Figure 7).

Here we have shown that VEGFR-1 participates in intracellular signal transduction and mediates biologic activity, specifically cellular migration, in human CRC cells. The expression of this receptor protein tyrosine kinase in tumour cells may further amplify signalling pathways already activated in colon tumour cells. Thus, VEGFR-mediated signalling offers novel targets for therapeutic interventions, either by targeting the receptor itself or important downstream mediators, such as Src. As Src activity has been shown to regulate VEGF expression, particularly under hypoxic conditions, in CRC cells (Ellis et al, 1998), the existence of an autocrine signalling loop capable of enhancing tumour survival and progression is intriguing. Delineating the mechanisms by which individual receptor tyrosine kinases mediate biologic activity in tumour cells is crucial for defining tumour-specific targets for optimal therapy. As recent work has demonstrated the presence of VEGFR-1 in multiple colon cancer cell lines and in both primary and metastatic tumour samples (Fan et al, 2005), VEGFR-1 may be a relevant clinical target, not only for its expression in endothelial cells but also for its expression/function in tumour cells.

\section{ACKNOWLEDGEMENTS}

This research was supported in part by NIH U54 CA 090810 (GEG), NIH R01 CA 112390 (LEM), The Lockton Fund for Pancreatic Research (LME, GEG), NIH T32 CA 09599 (DPL, JGT) and The Eleanor B Pillsbury Fellowship-University of Illinois Hospital (JGT).

\section{REFERENCES}

Ahmad SA, Liu W, Jung YD, Fan F, Wilson M, Reinmuth N, Shaheen RM, Bucana CD, Ellis LM (2001) The effects of angiopoietin-1 and -2 on tumor growth and angiogenesis in human colon cancer. Cancer Res 61: 1255 - 1259

Allgayer H, Boyd DD, Heiss MM, Abdalla EK, Curley SA, Gallick GE (2002) Activation of Src kinase in primary colorectal carcinoma: an indicator of poor clinical prognosis. Cancer 94: 344-351

Barleon B, Sozzani S, Zhou D, Weich HA, Mantovani A, Marme D (1996) Migration of human monocytes in response to vascular endothelial growth factor (VEGF) is mediated via the VEGF receptor flt-1. Blood 87: $3336-3343$

Bellamy WT, Richter L, Frutiger Y, Grogan TM (1999) Expression of vascular endothelial growth factor and its receptors in hematopoietic malignancies. Cancer Res 59: 728-733

Brown MT, Cooper JA (1996) Regulation, substrates and functions of src. Biochim Biophys Acta Rev Cancer 1287: 121 - 149

Brunton VG, Avizienyte E, Fincham VJ, Serrels B, Metcalf III CA, Sawyer TK, Frame MC (2005) Identification of Src-specific phosphorylation site on focal adhesion kinase: dissection of the role of $\mathrm{Src} \mathrm{SH} 2$ and catalytic functions and their consequences for tumor cell behavior. Cancer Res 65: $1335-1342$

Carmeliet P, Moons L, Luttun A (2001) Synergism between vascular endothelial growth factor and placental growth factor contributes to angiogenesis and plasma extravasation in pathological conditions. Nat Med 7: $575-583$

Cartwright CA, Kamps MP, Meisler AI, Pipas JM, Eckhart W (1989) pp60csrc activation in human colon carcinoma. J Clin Invest 83: 2025-2033

Chou MT, Wang J, Fujita DJ (2002) Src kinase becomes preferentially associated with the VEGFR, KDR/Flk-1, following VEGF stimulation of vascular endothelial cells. BMC Biochem 3: 32

Corbin AS, Demehri S, Griswold IJ, Wang Y, Metcalf III CA, Sundaramoorthi R, Shakespeare WC, Snodgrass J, Wardwell S, Dalgarno D, Iuliucci J, Sawyer T, Heinrich MC, Druker BJ, Deininge MW (2005) In vitro and in vivo activity of ATP-based kinase inhibitors AP23464 and AP23848 against activation loop mutants of Kit. Blood 106: $227-234$

Decaussin M, Sartelet H, Robert C, Moro D, Claraz C, Brambilla C, Brambilla E (1999) Expression of vascular endothelial growth factor (VEGF) and its two receptors (VEGF-R1-Flt1 and VEGF-R2-Flk1/KDR) in non-small cell lung carcinomas (NSCLCs): correlation with angiogenesis and survival. J Pathol 188: 369-377

Dias S, Hattori K, Heissig B, Zhu Z, Wu Y, Witte L, Hicklin DJ, Tateno M, Bohlen P, Moore MA, Rafii S (2001) Inhibition of both paracrine and autocrine VEGF/ VEGFR-2 signaling pathways is essential to induce long-term remission of xenotransplanted human leukemias. Proc Natl Acad Sci USA 98: $10857-10862$

Dias S, Hattori K, Zhu Z, Heissig B, Choy M, Lane W, Wu Y, Chadburn A, Hyjek E, Gill M, Hicklin DJ, Witte L, Moore MA, Rafii S (2000) Autocrine stimulation of VEGFR-2 activates human leukemic cell growth and migration. J Clin Invest 106: 511-521
Eliceiri BP, Paul R, Schwartzberg PL, Hood JD, Leng J, Cheresh DA (1999) Selective requirement for Src kinases during VEGF-induced angiogenesis and vascular permeability. Mol Cell 4: 915-924

Ellis LM, Staley CA, Liu W, Fleming RY, Parikh NU, Bucana CD, Gallick GE (1998) Down-regulation of vascular endothelial growth factor in a human colon carcinoma cell line transfected with an antisense expression vector specific for c-src. J Biol Chem 273: $1052-1057$

Fan F, Wey JS, McCarty MF, Belcheva A, Liu W, Bauer TW, Somcio RJ, Wu Y, Hooper A, Hicklin DJ, Ellis LM (2005) Expression and function of vascular endothelial growth factor receptor-1 on human colorectal cancer cells. Oncogene 16: $2647-2653$

Ferrer FA, Miller LJ, Lindquist R, Kowalczyk P, Laudone VP, Albertsen PC, Kreutzer DL (1999) Expression of vascular endothelial growth factor receptors in human prostate cancer. Urology 54: $567-572$

Hayashibara T, Yamada Y, Miyanishi T, Mori H, Joh T, Maeda T, Mori N, Maita T, Kamihira S, Tomonaga M (2001) Vascular endothelial growth factor and cellular chemotaxis: a possible autocrine pathway in adult T-cell leukemia cell invasion. Clin Cancer Res 7: 2719-2726

Hiratsuka S, Maru Y, Okada A, Seiki M, Noda T, Shibuya M (2001) Involvement of Flt-1 tyrosine kinase (vascular endothelial growth factor receptor-1) in pathological angiogenesis. Cancer Res 61: 1207-1213

Hiratsuka S, Minowa O, Kuno J, Noda T, Shibuya M (1998) Flt-1 lacking the tyrosine kinase domain is sufficient for normal development and angiogenesis in mice. Proc Natl Acad Sci USA 95: 9349-9354

Hurwitz H, Fehrenbacher L, Novotny W, Cartwright T, Hainsworth J, Heim W, Berlin J, Baron A, Griffing S, Holmgren E, Ferrara N, Fyfe G, Rogers B, Ross R, Kabbinavar F (2004) Bevacizumab plus irinotecan, fluorouracil, and leucovorin for metastatic colorectal cancer. $N$ Engl J Med 350: $2335-2342$

Irrthum A, Karkkainen MJ, Devriendt K, Alitalo K, Vikkula M (2000) Congenital hereditary lymphedema caused by a mutation that inactivates VEGFR3 tyrosine kinase. Am J Hum Genet 67: 295-301

Lacal PM, Failla CM, Pagani E, Odorisio T, Schietroma C, Falcinelli S, Zambruno G, D'Atri S (2000) Human melanoma cells secrete and respond to placenta growth factor and vascular endothelial growth factor. J Invest Dermatol 115: $1000-1007$

Leung DW, Cachianes G, Kuang WJ, Goeddel DV, Ferrara N (1989) Vascular endothelial growth factor is a secreted angiogenic mitogen. Science 246: 1306-1309

Maru Y, Hanks SK, Shibuya M (2001) The tubulogenic activity associated with an activated form of Flt-1 kinase is dependent on focal adhesion kinase. Biochim Biophys Acta 1540: $147-153$

Masood R, Cai J, Zheng T, Smith DL, Hinton DR, Gill PS (2001) Vascular endothelial growth factor (VEGF) is an autocrine growth factor for VEGF receptor-positive human tumors. Blood 98: 1904-1913

Meyer RD, Rahimi N (2003) Comparative structure-function analysis of VEGFR-1 and VEGFR-2: What have we learned from chimeric systems? Ann N Y Acad Sci 995: 200-207

Millauer B, Wizigmann-Voos S, Schnurch H, Martinez R, Moller NP, Risau W, Ullrich A (1993) High affinity VEGF binding and developmental 
expression suggest Flk-1 as a major regulator of vasculogenesis and angiogenesis. Cell 72: $835-846$

Minard ME, Herynk MH, Collard JG, Gallick GE (2005) The guanine nucleotide exchange factor Tiam1 increases colon carcinoma growth at metastatic sites in an orthotopic nude mouse model. Oncogene 24: 2568 2573

Munshi N, Groopman JE, Gill PS, Ganju RK (2000) c-Src mediates mitogenic signals and associates with cytoskeletal proteins upon vascular endothelial growth factor stimulation in Kaposi's sarcoma cells. I Immunol 164: 1169 - 1174

Neufeld G, Cohen T, Gengrinovitch S, Poltorak Z (1999) Vascular endothelial growth factor (VEGF) and its receptors. FASEB J 13: 9-22

O'Hare T, Pollock R, Stoffregen EP, Keats JA, Abdullah OM, Moseson EM, Rivera VM, Tang $\mathrm{H}$, Metcalf III CA, Bohacek RS, Wang $\mathrm{Y}$, Sundaramoorthi R, Shakespeare WC, Dalgarno D, Clackson T, Sawyer TK, Deininger MW, Druker BJ (2004) Inhibition of wild-type and mutant $\mathrm{Bcr}-\mathrm{Abl}$ by AP23464, a potent ATP-based oncogenic protein kinase inhibitor: implications for CML. Blood 104: $2532-2539$

Park J, Meisler AI, Cartwright CA (1993) c-Yes tyrosine kinase activity in human colon carcinoma. Oncogene 8: 2627-2635

Summy JM, Gallick GE (2003) Src family kinases in tumor progression and metastasis. Cancer Metastasis Rev 22: 337 - 358

Summy JM, Trevino JG, Lesslie DP, Baker CH, Shakespeare WC, Wang Y, Sundaramoorthi R, Metcalf III CA, Keats JA, Sawyer TK, Gallick GE (2005) AP23846, a novel and highly potent Src family kinase inhibitor, reduces vascular endothelial growth factor and interleukin- 8 expression in human solid tumor cell lines and abrogates downstream angiogenic processes. Mol Cancer Ther 4: 1900-1911

Takahashi Y, Tucker SL, Kitadai Y, Koura AN, Bucana CD, Cleary KR, Ellis LM (1997) Vessel counts and expression of vascular endothelial growth factor as prognostic factors in node-negative colon cancer. Arch Surg 132: $541-546$

Talamonti MS, Roh MS, Curley SA, Gallick GE (1993) Increase in activity and level of pp60c-src in progressive stages of human colorectal cancer. J Clin Invest 91: $53-60$

Thomas SM, Brugge JS (1997) Cellular functions regulated by Src family kinases. Annu Rev Cell Dev Biol 13: 513-609

Ueda Y, Yamagishi T, Samata K, Hirayama N, Aozuka Y, Tanaka M, Nakaike S, Saiki I (2005) Antitumor effects of synthetic VEGF-receptor binding antagonist, VGA1155. Anticancer Res 25: 3973 - 3977

Waltenberger J, Claesson-Welsh L, Siegbahn A, Shibuya M, Heldin CH (1994) Different signal transduction properties of KDR and Flt1, two receptors for vascular endothelial growth factor. J Biol Chem 269: 26988-26995

Wang ES, Teruya-Feldstein J, Wu Y, Zhu Z, Hicklin DJ, Moore MA (2004) Targeting autocrine and paracrine VEGF receptor pathways inhibits human lymphoma xenografts in vivo. Blood 104: 2893-2902

Werther K, Christensen IJ, Brunner N, Nielsen HJ (2000) Soluble vascular endothelial growth factor levels in patients with primary colorectal carcinoma. The Danish RANX05 Colorectal Cancer Study Group. Eur J Surg Oncol 26: 657-662

Windham TC, Parikh NU, Siwak DR, Summy JM, McConkey DJ, Kraker AJ, Gallick GE (2002) Src activation regulates anoikis in human colon tumor cell lines. Oncogene 21: $7797-7807$ 